\title{
Sandra Patrício
}

\section{Universidade de São Paulo}

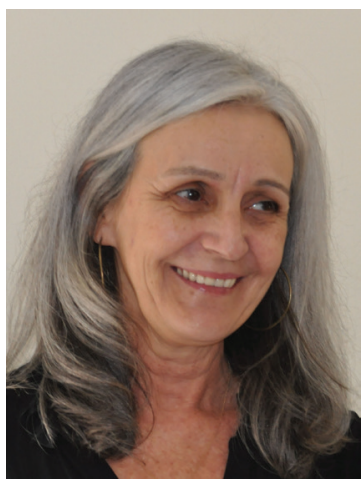

Docente do Instituto de Psicologia da Universidade de São Paulo e orientadora do Programa de Pós-Graduação em Psicologia Social. Vice coordenadora do Laboratório de Psicologia Socioambiental e Intervenção (IPUSP); líder do Grupo de Pesquisa Mitopoética da Cidade (IPUSP); membro colaborador do Grupo de Pesquisa em Política Ambiental (IEA-UsP) e do Centro de Filosofia da Universidade de Lisboa.

cv: http://lattes.cnpq.br/6404152265871629

E-MAIL: sandrapatrício@usp.br orciD: https://orcid.org/oooo-0oo2-3838-122X 


\section{Vladimir Bartalini \\ Universidade de São Paulo}

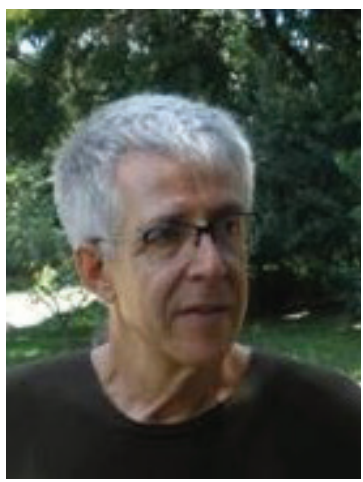

Docente da Faculdade de Arquitetura e Urbanismo da Universidade de São Paulo e orientador do Programa de Pós-Graduação em Arquitetura e Urbanismo. Membro fundador do Laboratório Paisagem, Arte e Cultura - LABPARC/ FAU-USP, que coordenou de 2002 a 2006. Desenvolve estudos teóricos sobre paisagem e pesquisa sobre "Córregos Ocultos" e atua profissionalmente em projetos e consultorias em Paisagismo, sobretudo em espaços livres, áreas verdes e parques públicos.

cv: http://lattes.cnpq.br/2952247331062910

E-MAIL: bartalini@usp.br orciD: https://orcid.org/0000-0002-3412-0620 
Considerações sobre a gravidade ética e política da paisagem e de suas transformações

RESUMO: Este ensaio aborda duas perspectivas divergentes sobre a paisagem, uma que acentua a vertente subjetiva da representação e outra que acentua a vertente objetiva dos espaços, buscando mostrar uma terceira dimensão ontológica, específica da paisagem - uma dimensão trajectiva, que faz dela uma categoria sintética entre natureza e cultura. Neste sentido, a paisagem expressa o modo singular como, ao longo dos tempos, se integraram as dimensões físico-biológicas e histórico-culturais num dado território. Estas considerações conferem relevo ético e político à noção de paisagem: se sua integridade (aliás, poderíamos até dizer: sua beleza) expressa formalmente a relação harmônica entre o lugar e a vida de seus habitantes, sua transformação além de certos limites (poderíamos dizer: sua deformidade) é sintoma de desarmonias passadaspresentes e permite vislumbrar desequilíbrios e sofrimentos futuros.

PALAVRAS-CHAVE: PAISAGEM, TRAJECTIVIDADE, CIDADE, RIOS ocUltos, ÉTICA. 
A perspective for the understanding of the human ethos

ABSTRACT: This essay

approaches two divergent perspectives about the landscape, one that emphasizes the subjective side of representation and another that accentuates the objective side of spaces, seeking to show a third ontological dimension, specific to the landscape - a trajective dimension, which makes landscape into a synthetic category between nature and culture. In this way, the landscape expresses the singular way in which, over time, the physicalbiological and historicalcultural dimensions have been integrated into a given territory. These considerations give ethical and political importance to the notion of landscape: if its integrity (we could even say: its beauty) formally expresses the harmonious relationship between the place and the life of its inhabitants, its transformation beyond certain limits (we could say: its deformity) is a symptom of past-present disharmonies and allows us to glimpse future imbalances and sufferings.

KEYWORDS: LANDSCAPE, TRAJECTIVITY, CITY, HIDDEN RIVERS, ETHIC. 



\section{Considerações sobre a gravidade ética e política da paisagem e de suas transformações}

\section{Sandra Patrício}

Universidade de São Paulo Vladimir Bartalini Universidade de São Paulo

Adiantamos que estas breves considerações têm modesta pretensão, qual seja, a de tão somente oferecer algumas reflexões que, a nosso ver, podem abrir caminho entre duas perspectivas divergentes sobre a paisagem, uma que acentua a vertente subjetiva da representação e outra que acentua a vertente objetiva dos espaços. Pensamos que se trata de uma cisão equivocada e que sua superação poderá permitir o reconhecimento de uma terceira dimensão ontológica, específica da paisagem: nem tão só subjetiva, nem tão só objetiva, mas trajectiva. Estamos certos de que isto pode trazer uma compreensão ética que, queremos crer, colocaria em novas e melhores bases o debate político sobre a paisagem.

Nesta direção, começaremos por apresentar alguns esclarecimentos preliminares sobre os termos “ocupação socioespacial”, 
"território" e "metamorfose" pois, embora distintos, seus conteúdos tangenciam-se e, às vezes, imbricam-se, tanto que, sob outros nomes, eles já deram motivo a reflexões que nos interessam de perto. Afinal, "metamorfose", que diz respeito à forma, remete à paisagem, ao passo que "ocupação socioespacial", a ambiente. Com o acréscimo de "território", chega-se ao título do texto escrito por Rosario Assunto, em 1976: "Paesaggio, Ambiente, Territorio. Un tentativo di precisazione concettuale".

Estamos, portanto, tratando do ambiente de um território e das mudanças que ocorrem na sua paisagem. Estes três vocábulos - território, ambiente, paisagem - são muitas vezes usados indiscriminadamente como se houvesse uma equivalência entre eles. Rosário Assunto aplicou-se em desmontar este pressuposto que obscurece diferenças importantes, com consequências que não se encerram no mundo dos conceitos, mas atingem a prática. Para ele, território é matéria, extensão, superfície mais ou menos vasta, cujas delimitações podem ser definidas por critérios político-administrativos, culturais ou geofísicos. Um território permanece idêntico a si mesmo, independente das alterações que venham a ocorrer na sociedade que o ocupa ou das variações bio-climáticas que o atinjam. No seu esforço de esclarecimento conceitual, de início discriminador, Assunto cogita a imutabilidade de um território, mesmo no caso extremo da destruição total da sociedade e do ambiente biológico que lhe correspondem.

Interessante notar, de passagem, como hipótese semelhante foi aventada por Milton Santos para estabelecer a diferença entre paisagem e espaço: "A rigor, a paisagem é apenas a porção da

1 Rosario Assunto, "Paisagem, Ambiente, Território. Uma tentativa de clarificação conceptual”, in SERRÃo, Adriana Veríssimo (coord.), Filosofia da paisagem. Uma antologia. Lisboa, Centro de Filosofia da Universidade de Lisboa, 2011, pp. 126-129. 
configuração territorial que é possível abarcar com a visão, e se dá como um conjunto de objetos reais-concretos" ${ }^{2}$ e, por mais que estes objetos interfiram no espaço, “só por sua presença, os objetos técnicos não têm outro significado senão o paisagístico”3. No pensamento de Milton Santos, é preciso que um conteúdo social anime estes objetos e, na distinção operada entre paisagem e espaço, caberia àquela o papel de matéria inerte, destituída de vida. É necessário, portanto, cautela no emprego dos termos e atenção para os limites da sua validade em função do pensamento de quem os emprega. Caso contrário, poderíamos incorrer no erro de dizer que, para Rosario Assunto, território e paisagem são sinônimos.

Prossigamos então com este pensador, Rosario Assunto, o qual, após discorrer sobre o conceito de território, se ocupa em verificar se este conceito equivaleria ao de ambiente. Ele discerne duas dimensões no ambiente: uma, físico-biológica - latitude, longitude, altitude, clima, fauna, flora, geologia, relevo, hidrografia, etc - e outra, histórico-cultural - economia, política, costumes, idiomas, etc. É fácil, diz ele, perceber que o conceito de ambiente, "na sua unidade-diversa de ambiente biológico e de ambiente histórico-cultural, inclui em si o de 'território' (não pode haver ambiente sem território), mas com um excesso de elementos que não são necessários para a definição de território enquanto tal"4. O ambiente, portanto, seria o território qualificado em termos físico-biológicos e histórico-culturais. Não nos parece ousado aproximá-lo da expressão “ocupação socioespacial”, se considerarmos que nela estão contidos, de modo sintético e inextricável, a sociedade, em sua dinâmica histórica, e a sua expressão material, concreta, física

\footnotetext{
2 Milton Santos, A natureza do espaço. São Paulo, Edusp, 2002, 4 edição, p. 104.

3 Idem, p. 105.

4 Rosario Assunto, op. cit., p. 127.
} 
(mais uma vez, cumpre ressaltar as diferenças de acepção que a palavra espaço assume nos diferentes autores. Para Milton Santos, o espaço não poderia ser assumido, como fica sugerido pela aproximação que acabamos de fazer, como a expressão concreta, meramente material, da sociedade). Assim, para Rosario Assunto o ambiente seria "o território acrescido da vida, da história, da cultura", o que já impede a substituição indiscriminada de um conceito pelo outro. Parece-nos lícito, portanto, considerar que uma tal concepção de ambiente, ou seja, como sendo "o território vivo para o homem e vivido pelo homem"6, equivale ao espaço de Milton Santos.

Até aqui, estas considerações podem dar a impressão de que nos limitamos a cotejar conceitos que dizem respeito aos mesmos fatos ou fenômenos, mas que recebem nomes diferentes conforme os diferentes pensadores que sobre eles se debruçaram. Ao introduzir o seu conceito de paisagem, porém, Assunto não só lhe atribui um significado diverso daquele que lhe emprestará a geografia crítica miltoniana, como a reintegra numa unidade com o território e com o ambiente, o que passa a nos interessar de modo especial. Assim, uma vez incluído o conceito de território no de ambiente, Assunto define a paisagem como a "forma" que o ambiente ("conteúdo" ou "função") confere ao território ("matéria”). Mas não se trata de uma forma inerte, limitada a deixar-se abarcar pela visão, e sim de uma forma "na qual se exprime a unidade sintética a priori da 'matéria' (território)' e do 'conteúdo-ou-função' (ambiente)”,7.

5 Idem, p. 128.

6 Idem, ibidem.

7 Idem, ibidem.

8 Cumpre notar que Rosário Assunto está, declaradamente, empregando a expressão "unidade sintética a priori” no sentido kantiano, ou seja, no sentido de unidade necessária que condiciona o seu apresentar-se na consciência (Idem, p. 128). 
Esta definição de paisagem não deve ser julgada como simples preciosismo conceitual, como pura abstração. Para Assunto, abstração seria o território, ao qual só poderíamos ter acesso mediante a abstração do ambiente que o modela com "as nossas esperanças e desilusões, as nossas alegrias e as nossas tristezas”; abstração seria também o ambiente, "assim como seria abstração irreal o conteúdo de um livro (...) sem a realidade em que ele se exprime modelando uma matéria verbal" " Em suma, só temos acesso ao território e ao ambiente por meio da paisagem, que nos permite viver, experienciar e conhece-los na sua "indissolúvel unidade". Se o conceito de ambiente abarca o de território, o de paisagem abarca o de ambiente. As consequências práticas que daí advêm são fundamentais para nós, como se pode conferir nas palavras com as quais Assunto conclui o seu breve mas elucidativo ensaio: "a realidade que devemos estudar e sobre a qual, se necessário, devemos intervir é sempre a 'paisagem', e não o ‘ambiente' e muito menos o ‘território’”'

\section{A FORMA DA PAISAGEM}

A não observância destas distinções tem reflexos muitas vezes deletérios pois, ao esvaziá-la de seu caráter sintético, abre-se caminho para a legitimação de ag ressões violentas que deformam a paisagem, a qual pode ser considerada a fisionomia, o rosto (este objeto privilegiado dos nossos afetos e afecções) da Terra. Confundida e reduzida a puro espaço geométrico, reificada, a paisagem deixa de entrar nas cogitações dos projetistas de estradas (Rosario Assunto investe contra a insensibilidade dos engenheiros

9 Idem, p. 129.

10 Idem, ibidem. 
responsáveis pelo traçado das rodovias que atravessam a planície do Pó, para os quais ela não parecia suave, como a cantaram os poetas, mas simplesmente lisa, pronta a receber o que a "régua e o tira-linhas" determinassem ${ }^{11}$. Infelizmente, poderíamos contribuir com muitos outros exemplos de procedência nacional), dos construtores de edifícios, enfim, de tantos atores que desfrutam e abusam da autoridade para intervir nas nossas paisagens sem nos consultarem.

Nada do que foi dito implica a defesa da imobilidade, uma cristalização mórbida da paisagem. Se a paisagem tem fisionomia, rosto, ela é dotada de expressividade, de vida, portanto está sempre em transformação: por assim dizer, ela é forma em trânsito. Porém, como todo rosto que não foi deformado a ponto de se tornar irreconhecível, ela se modifica sem impedir o seu reconhecimento, o que permite a preservação e a renovação das tonalidades afetivas que nos fazem distinguir uma paisagem de outra.

Sim, "a paisagem se unifica em torno de uma tonalidade afetiva dominante", diz Eric Dardel, o que a legitima enquanto fenômeno, ainda que ela seja "refratária a toda redução puramente científica”. A paisagem, continua Dardel, "põe em jogo a totalidade do ser humano, seus vínculos existenciais com a Terra (...) como lugar, base e meio de sua realização (numa) relação que afeta a carne e o sangue” ${ }^{12}$.

A paisagem não é, em sua essência, para ser vista. Esta assertiva de Dardel pode soar estranha à primeira vista, mas a entendemos, antes, como uma provocação, como uma força de expressão para se contrapor à concepção dominante, ao menos desde a aurora da

11 Rosario Assunto, "A paisagem e a estética”, in SERRÃo, Adriana Veríssimo (coord.), Filosofia da paisagem. Uma antologia. Lisboa, Centro de Filosofia da Universidade de Lisboa, 2011, p. 342.

12 Eric Dardel, L’Homme et la Terre. Nature de la réalité géographique. Paris, editions du cTHS, 1990, p. 42. 
modernidade, que limita a paisagem ao campo visual que se descortina de um lugar alto. Do mesmo modo que podem parecer desconcertantes as conclusões de Jean-Marc Besse no instigante ensaio intitulado "Nas dobras do mundo. Paisagem e filosofia segundo Péguy"'3. Retomando as ideias de Charles Péguy, pensador francês do início do século xx, que concebia a filosofia como ação no universo pensante, Besse pode dizer que "o melhor ponto de vista para o mundo é o ponto de vista de baixo, e que sobe para as coisas, apoderando-se assim do impulso do ser. Visto de cima, o mundo é plano. É por baixo que é preciso começar, é ali que é preciso ficar, ou retornar, para se lançar"14.

No entanto, não se trata de negar que a paisagem seja da ordem do visível e, mais ainda, do estético. Afinal, como salienta Jean-Marc Besse, agora num alentado posfácio à reedição de L'Homme et la Terre, “a estética é a primeira ligação do homem com o mundo, sua primeira maneira de se situar nele, de compreendê-lo"15. E o próprio Dardel, no mesmo sub-tópico em que se empenhava na recusa em reduzir a essência da paisagem à mera visualidade, declara que "há na paisagem um rosto, um olhar, uma escuta, uma expectativa ou uma reminiscência"16. A paisagem é um rosto (visage, em francês; viso, em italiano), e um rosto só é rosto porque é visto, e o rosto só é visto quando se está fora do corpo, por aquele que vê o rosto de um "outro", ou o próprio rosto refletido, circunstância em que também já se é um “outro”.

13 Jean-Marc Besse, Ver a Terra. Seis ensaios sobre a paisagem e a geografia. Tradução Vladimir Bartalini. São Paulo, Perspectiva, 2006, pp. 97-108.

14 Jean-Marc Besse, "Nas dobras do mundo. Paisagem e filosofia segundo Péguy", op. cit., p. 105 .

15 Jean-Marc Besse, “Geographie et existence, d’aprés l'oeuvre d’ Eric Dardel”, in DARDEL, Eric, op. cit., p. 173 .

16 Eric Dardel, op. cit., p. 45. 
É na perspectiva aqui alinhavada, que não reduz a paisagem à "invenção" de um sujeito, tampouco à mera objetualidade; que pressupõe uma presença do homem indissociável de um mundo concreto onde ele realiza a sua existência; que não a limita ao campo perceptivo da visão, embora admita a sua imprescindibilidade; que considera a memória e, ao mesmo tempo, as aberturas para um futuro implícitas nos horizontes das paisagens; que vê a paisagem como imagem do tempo, na qual a temporalidade da natureza se coloca como fundamento da temporaneidade do mundo humano ${ }^{17}$ ("um vale encaixado, onde se manifesta o trabalho prolongado das águas, carrega o espírito para as profundezas da duração, de um tempo apreendido como fator secreto da Terra"18, diz Dardel); é nesta perspectiva que faz sentido, para nós, discutir a ocupação socioespacial no âmbito territorial brasileiro e, especificamente, as transformações incidentes sobre as paisagens das nossas cidades. Por isto, fazemos nossas as palavras de Adriana Serrão (2013):

Uma vez libertas da tradicional associação à vista, ao cenário e ao panorama, o entendimento das paisagens como unidades integradas e espaços do habitar permitirá conciliar o fundamento natural com dimensões constitutivamente humanas, como a História e a Cultura, e responderá mais facilmente a problemas candentes do tempo presente e futuro, desde o desenho das cidades até à invenção de formas de viver alternativas. ${ }^{19}$

17 Rosario Assunto, “A paisagem e a estética”, op. cit., p. 349-350.

18 Eric Dardel, op. cit., p. 45.

19 Adriana Veríssimo Serrão, Filosofia da Paisagem. Estudos. Lisboa, Centro de Filosofia da Universidade de Lisboa, 2013, p. 103. 


\section{A TRANSFORMAÇÃO DA PAISAGEM}

Gostaríamos de explicar este ponto o melhor possível e talvez seja útil recorrer a uma ilustração - começaremos propondo ao leitor algumas imagens de paisagens que se transformaram ao longo do tempo histórico, do tipo que certamente todos já tiveram ocasião de olhar. As que selecionamos, colhidas duma mesma área de São Paulo, recobrem um arco temporal de quase dois séculos. A primeira delas (Fig. 1a) é uma aquarela de Jean Baptiste Debret (1827), intitulada "Ponte de Santa Ifigênia"; Márcio Pereira Santos (2006), apresenta-nos o provável enquadramento do desenho conforme reproduzimos na Figura $\mathrm{lb}$ (a figura consiste em um recorte do "Mapa" elaborado por Santos, ligeiramente modificado para destacar o sítio em pauta) ${ }^{20}$.

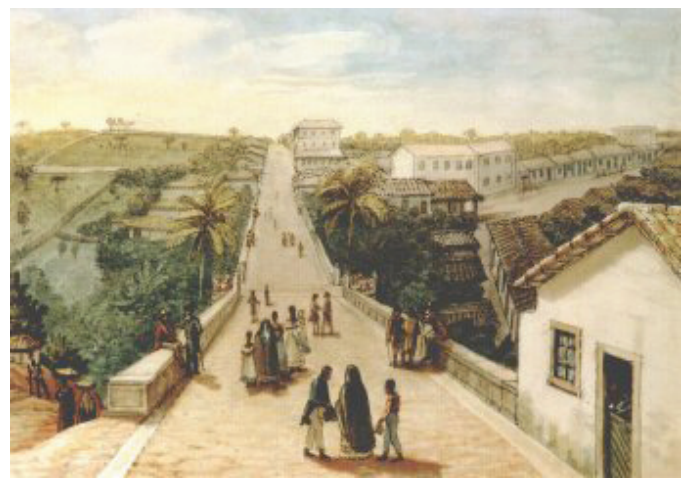

Figura 1a - "Ponte de Santa Ifigênia", aquarela de Jean Baptiste Debret (1827)

20 Márcio Pereira Santos. "O Espaço humanizado, a Paisagem humanizada e algumas reflexões sobre a paisagem em São Paulo na primeira metade do século XIX”. Tese (Doutorado), Faculdade de Filosofia, Letras e Ciências Humanas, Departamento de Geografia, Universidade de São Paulo, São Paulo, 2006. O “Mapa” supra mencionado constitui um anexo da tese e está disponível em: file:///C:/Users/m/Desktop/MAPA_DA_PAISAGEM.pdf (acesso: 14/02/2015). 


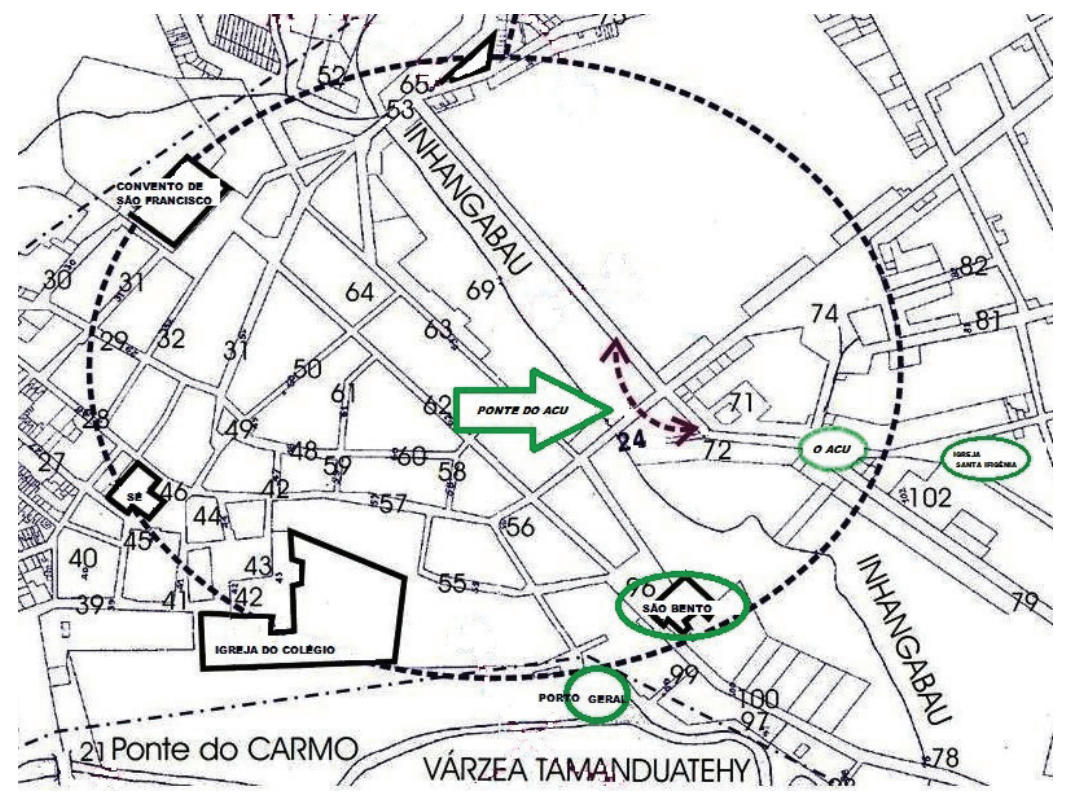

Figura 1b - Ângulo e distância aproximada da visão de Jean-Baptiste Debret (linha tracejada violeta, próxima à Ponte do Acu), aquando da execução da aquarela "Ponte de Santa Ifigênia", em 1827. Fonte: "Mapa de localização aproximada das diferentes representações em paisagem de São Paulo entre 1817 e 1847 a partir da interpretação das iconografias tendo por base a Carta de 1841", de Márcio Pereira Santos(2006), disponível em: file://C:/Users/m/Desktop/MAPA_DA_PAISAGEM.pdf (acesso: 14/02/2015).

À época, a ponte retratada por Debret fazia a ligação entre as duas margens do rio Anhangabaú, na altura da então chamada Ladeira do Acu que, após mudar de nome muitas vezes, é o caminho hoje conhecido como Av. São João. Para pontuarmos as transformações, seguem quatro imagens da mesma localidade (embora com enquadramentos diferentes) registradas em 1862 (Figura 2), 1930 (Figura 3), 1970 (Figura 4) e 2008 (Figura 5). 


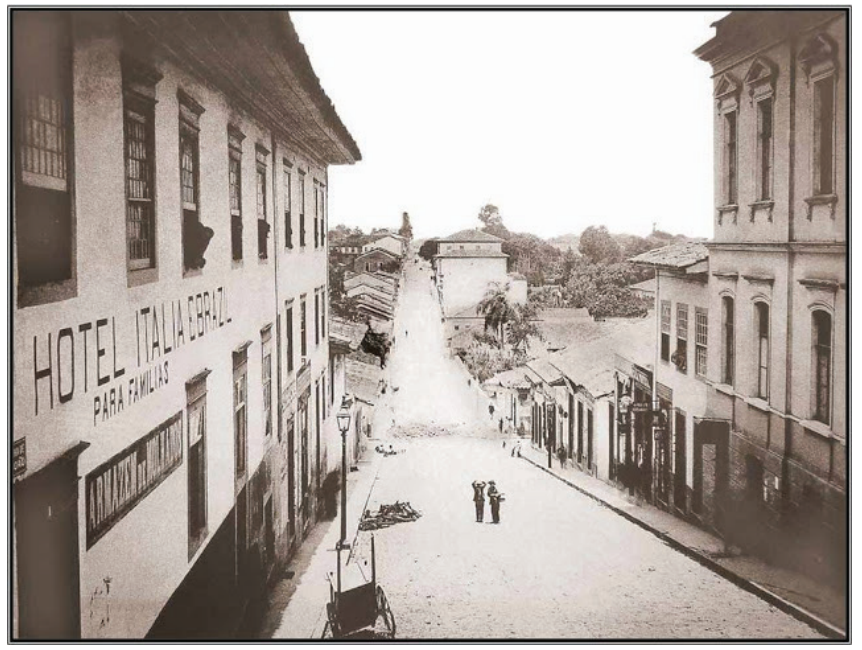

Figura 2 - Ladeira de São João em 1862. Fotografia de Militão de Azevedo.

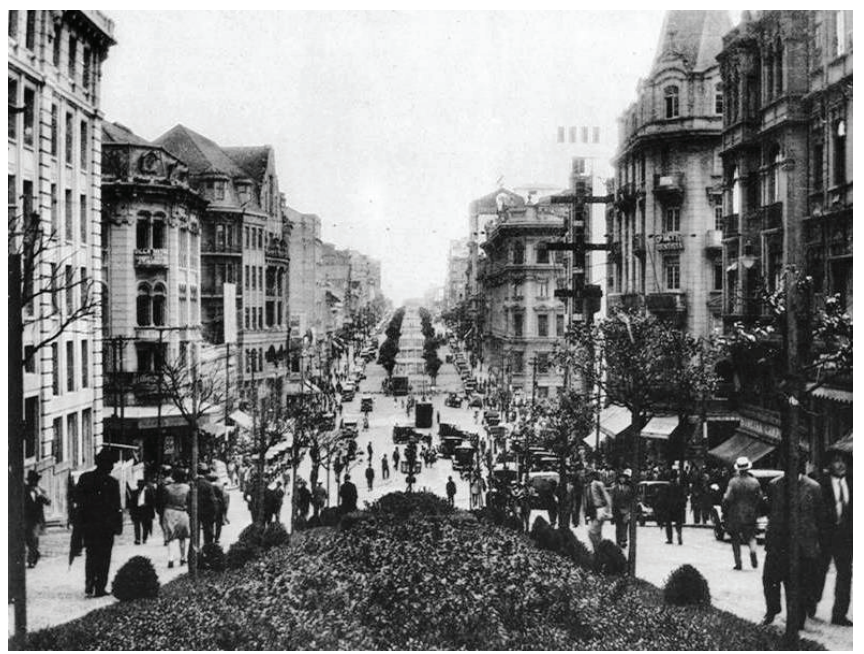

Figura 3 - Avenida São João em 1930. Fonte: ELETROPAUlo. A Cidade da Light. 1899/1930. Departamento de Patrimônio Histórico/Eletropaulo, 1990. 


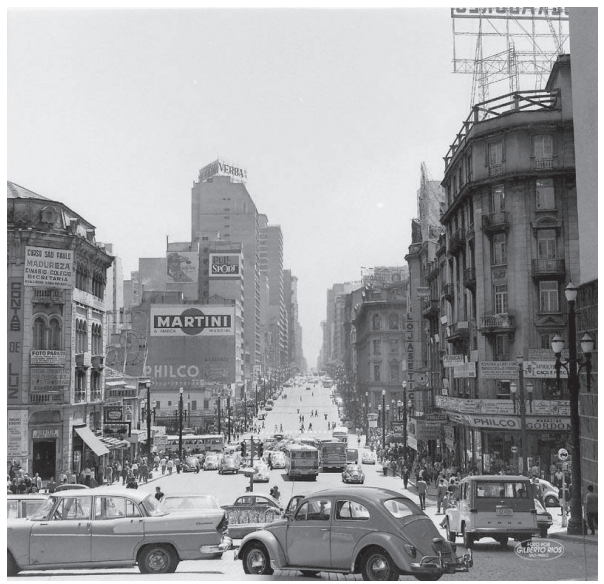

Figura 4 - Avenida São João em 1970. Fotografia de Gilberto Calixto Rios.

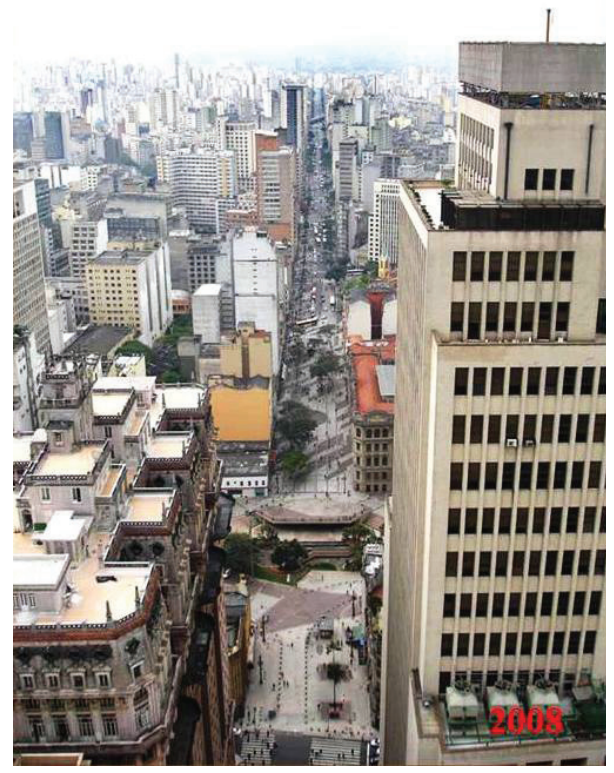

Figura 5 - Avenida São João em 2008. Fotografia de Gilberto Calixto Rios. 
Acreditamos que tais imagens, dispostas assim cronologicamente, prestarão auxílio para que possamos explicitar melhor os apontamentos feitos anteriormente. Antes de mais, não há dúvida de que estas imagens tenham sido colhidas, registradas, num único e mesmo território e de que, inobstante, tanto o ambiente quanto a paisagem não se mantiveram os mesmos. Mas, para que não haja confusão nos passos seguintes, vamos antes relembrar que temos diante de nós: 1) a idéia de um território, concebido como um recorte arbitrário de certa extensão material que abrange, no caso, uma certa colina às margens de certo curso d'água; 2) cinco imagens artísticas deste território, registradas por diferentes pessoas, em diferentes meios e em momentos distintos ao longo de duzentos anos;3) cinco formas diferentes correspondentes a este mesmo território, em cinco momentos diferentes de sua existência. Ora, mas estas formas apresentam-se tão diferentes, a mudança é tão radical, tão espetacular, que, mesmo quando se acaba de ler e pensar sobre as dimensões da paisagem que transcendem sua visibilidade, pode-se facilmente reincidir na espécie de simplificação que tende a considerar apenas as mudanças ocorridas no panorama, negligenciando aquelas que, necessariamente, se deram em aspectos, digamos, "menos visíveis" da paisagem. Esta simplificação é, justamente, o que o conceito de paisagem delineado nas linhas precedentes pretende superar e, nesta direção, relembramos também o que há pouco dissemos: a paisagem, sim, é uma forma visível, porém, uma forma que possui uma natureza muito particular: a paisagem é, como diz Rosário Assunto, a "forma" que o ambiente ("conteúdo" ou "função") confere ao território ("matéria”), uma forma "na qual se exprime a unidade sintética a priori da 'matéria' (território)' e do ‘conteúdo-ou-função' (ambiente)” - ou, em outras palavras, a paisagem é a forma gerada pelas ações de um conjunto 
singular de seres diversos (o conjunto de seres que constituem o ambiente, em suas dimensões físico-biológica e histórico-cultural), que operam conjuntamente em um dado território.

Nas imagens apresentadas acima nota-se facilmente as mudanças na hidrografia, sobretudo com a canalização do Anhangabaú, e outras - menos notáveis, é certo - que ocorreram no relevo. Por outro lado, a simples reflexão sobre o adensamento das construções e da população humana que estas imagens mostram já nos permitiria supor alterações significativas na temperatura, nos ventos, na composição do ar e da terra etc., mesmo que ignorássemos os dados científicos sobre o assunto. Quanto à flora, nem é preciso assinalar as mudanças, de tão evidentes que são; já quanto à fauna, a ausência de quaisquer outras espécies animais além da humana em todas estas gravuras, mesmo nas mais antigas, mereceria um comentário à parte, ao qual, porém, somos forçados a renunciar em favor da brevidade. É claro que as imagens retratam, também, as mudanças no ambiente histórico-cultural, que se destacam ao nosso olhar através de elementos concretos tais como a presença (ou ausência) e o tipo de vegetação, o uso (ou o desaparecimento) do ribeirão e suas margens, as formas das construções, das vestimentas, dos utensílios, e assim por diante.

\section{A UNIDADE-DIVERSA DA PAISAGEM}

Em suma, pode-se dizer que as imagens apresentadas acima são registros de formas que aquele território apresentou em determinados momentos; cada uma destas imagens corresponde a uma fisiognomia diferente do mesmo território - cada uma destas fisiognomias poderiam ser consideradas como paisagens inteiramente diferentes? 
Sim, se estancarmos na consideração estética da paisagem - e, mesmo assim, precisaríamos restringir o alcance da palavra "estética" ao escopo da visualidade. Isto feito, pareceria que a fisiognomia do território (que seria, então, o mesmo que "a paisagem") nada mais é que uma espécie de espetáculo, apreciado por diferentes espectadores como mais ou menos belo (de acordo com sua posição, interesses ou “gosto”). Neste espetáculo, seriam representadas as escolhas feitas pelas sociedades humanas que habitaram o dito território ao longo da história, escolhas estas que seriam convertidas pelos atores, com maior ou menor liberdade, em ações mais ou menos engenhosas e bem sucedidas - na situação que as nossas imagens vieram ilustrar: primeiro, com Debret, o cenário (e a cena) de uma sociedade colonial e escravagista em vias de urbanização; depois, ao final do século XIX, cidade em franco crescimento, onde aportavam os imigrantes europeus que viriam a impulsionar a lavoura cafeeira no interior do estado; em seguida, parte nobre de uma cidade progressista, a espelhar o melhor possível o sofisticado modelo europeu; em 1970, as marcas de uma cidade decididamente americanizada; finalmente, a megalópole enigmática de hoje em dia.

Nada disso é falso e, todavia, não nos parece bastar. Insistimos em que cada uma das imagens acima nos apresenta um "flagrante" da forma do território, tal como estava moldada pelo “ambiente", ou seja, pelos seres físico-biológicos e pelos seres histórico-culturais que existiam e interagiam naquele território num dado momento (e não se descura que este "flagrante" esteja marcado pela visão particular do artista que o registrou; de qualquer modo, há que se lembrar, também, que tal artista era, ele próprio, partícipe do referido ambiente). Então, à mudança visível da paisagem deve corresponder uma mudança (visível ou invisível) 
nesta "unidade-diversa" que a constitui - e a nossa aposta é de que tais mudanças sejam inteligíveis.

Permitam-nos interpolar aqui um ligeiro alerta, provavelmente desnecessário para os mais doutos, mas importante para aqueles que se iniciam nestas discussões. Temos dito, ressoando Rosário Assunto e outros pensadores não mencionados, que a paisagem é uma "unidade-diversa". É preciso dizer que esta expressão deve levar-nos a considerar seriamente o fato de que, embora toda e qualquer paisagem apresente uma composição de diversos elementos individuais (digamos: um rio, árvores, talvez algumas construções etc.), nós a percebemos, enquanto paisagem, como um todo unitário ${ }^{21}$. Ora, isto não é banal. Considerar a paisagem como "unidade-diversa", por um lado, exige pressuposições a respeito de como podemos aperceber-nos de um todo, partindo da visão de um conjunto de elementos individuais e, por outro lado, a respeito do que é minimamente necessário existir neste "conjunto" para que possamos apercebe-lo como "uma paisagem”. Para que o alerta seja mesmo ligeiro, vamos resumir tudo dizendo que, mesmo quando não estamos inteiramente cônscios disto, precisamos de uma teoria do conhecer e de uma teoria do ser, antes que possamos compreender a paisagem. Naturalmente, não poderíamos avançar nestas questões teóricas aqui. Mas também não poderíamos omitir que a consideração da paisagem como "unidade-diversa”, ao mesmo tempo que não renega, mas amplia sua consideração estética, pressupõe que a paisagem tem uma

21 Sobre este tópico, veja-se o ensaio de Georg Simmel (1913), In: SERRÃo, Adriana Veríssimo (coord.), Filosofia da paisagem. Uma antologia. Lisboa, Centro de Filosofia da Universidade de Lisboa, 2011, p. 42-51. Este ensaio é retomado por Adriana Serrão para discutir a paisagem como "intuição momentânea da Vida", em: SERRÃO, Adriana Veríssimo. Filosofia da Paisagem. Estudos. Lisboa, Centro de Filosofia da Universidade de Lisboa, 2013, p. 161-164. 
profundidade ontológica própria, que faz dela uma categoria sintética entre natureza e cultura ${ }^{22}$.

Voltando à nossa ilustração, a tomada que estamos defendendo pretenderia fazer relevar desta sucessão temporal de formas momentâneas assumidas pelo território em pauta - o qual, sob outras formas, já existia antes de 1827 e seguirá existindo indefinidamente após 2008, provavelmente sob novas formas - alguma compreensão sobre o devir de sua paisagem. Nesta tomada, faz muito pouco sentido dizer que cada uma das imagens que estamos tratando representa uma paisagem diferente, característica de um tempo histórico diferente - o que realmente importa é a indagação sobre a gravidade destas transformações visíveis em sua composição físico-biológica e histórico-cultural.

\section{A GRAVIDADE DA PAISAGEM}

Aqui, a palavra grave figura primeiramente como adjetivo: a paisagem é algo que tem peso, importância, poder; precisa ser ponderada com seriedade. Mas poderá ser útil lembrar que, em nossa língua, a palavra 'grave' pode ser empregada com um segundo sentido, para a conjugação do verbo 'gravar' nos modos subjuntivo (presente, $1^{\mathrm{a}}$ e $3^{\mathrm{a}}$ pessoas do singular, bem como na $2^{\mathrm{a}}$, na forma 'você') e imperativo ( $2^{\mathrm{a}}$ pessoa do singular, 'você'). Neste sentido, indica a ação de gravar, esculpir, estampar, imprimir, registrar.

22 Recomendamos fortemente que o leitor interessado busque os trabalhos publicados como resultados do projeto de pesquisa coletivo "Filosofia e Arquitectura da Paisagem", coordenado pela Dra. Adriana Veríssimo Serrão, no Centro de Filosofia da Universidade de Lisboa. Três deles encontram-se citados no corpo do presente texto e o quarto é: "Filosofia e Arquitectura da Paisagem. Intervenções" (2013).

Capítulo 2

Considerações sobre a gravidade ética e politica da paisagem e de suas transformações

Sandra Patrício e Vladimir Bartalini 
Talvez se possa extrair disto algo mais que uma ambiguidade fortuita ${ }^{23}$; no mínimo, há que se pensar numa possível reversibilidade, ou seja, que tanto a paisagem é "gravada", marcada, esculpida, formada, pelos seres diversos que a compõem, quanto que esta mesma paisagem, tal como esteja formada, possa ter uma importância, um peso e um poder próprios, que a torna capaz de, por sua vez, "gravar", esculpir, formar, estes mesmos seres - e, neste caso, estaríamos diante de uma forma de graves consequências.

$\mathrm{E}$, sim, se tomamos a paisagem como a forma que expressa o modo singular como, ao longo dos tempos, se integraram as dimensões físico-biológicas e histórico-culturais num dado território, logo percebemos que ela, por assim dizer, reflete a existência de tudo quanto nela se encontra, inclusive, reflete as particularidades de cada tipo de ser que a ocupa ou habita - coisa, idéia, valor ou vida. Neste sentido, qualquer mudança na paisagem deve ser vista com seriedade, pois estaria refletindo uma mudança qualquer em seus componentes. Ora, tratando-se de uma unidade integrada, qualquer mudança tem o potencial para repercutir tanto em cada um de seus elementos tomados individualmente como em cada tipo específico deles, como também em todo o conjunto - repercussão que pode ter consequências benignas ou malignas, nem sempre inteiramente previsíveis.

Esta reversibilidade está contemplada no conceito de trajeção proposto pelo geógrafo Augustin Berque, que o define como "combinação medial e histórica do subjetivo e do objetivo, do físico e do

23 Não deixa de ser instigante o caso do substantivo grego grámma, cujos significados incluem: 1) o resultado concreto do ato de "escrever / desenhar", 2) "letra, carta, inscrição" ou "desenho, pintura", 3) "letra, caráter" (donde grammatikós designava um indivíduo "versado em letras") e 4) um peso mínimo, equivalente a um pouco mais de um grama moderno. O assunto é exposto em detalhes em: BESSELAAR, José Van Den. "As palavras têm a sua história". Braga: Edições APPACDM, 1994, p. 401. 
fenomenal, do ecológico e do simbólico, produzindo uma mediância" ${ }^{24}$. Desta maneira, Berque aplica a palavra trajetividade para caracterizar a qualidade de coisas cuja realidade depende, ao mesmo tempo, de existência física (ou "objetiva") e mental (ou "subjetiva"), e é neste sentido que ele define paisagem como "dimensão sensivel e simbólica do meio; expressão de uma mediância”’s. Daí que ele próprio venha a dizer:

O humano aparece, assim, como [...] um ser que grava (graphein) sua existência na Terra (gê) sob a forma de geogramas e que, em troca, fica gravado em certo sentido; pois ele não seria ele mesmo (quer dizer, humano) sem a mediância desta relação ecumenal. Se, entretanto, concebemos que o humano grava a Terra com suas marcas, como pode ele, por sua vez, ser gravado por ela como por uma matriz? Se isso é possível, é porque a trajeção não é uma dinâmica em sentido único. Ela é um contínuo vaivém entre nosso corpo e o mundo. ${ }^{26}$

Estas considerações justificam nossa insistência em ressaltar a gravidade da paisagem e de suas alterações. A paisagem, já o dissemos, é forma em trânsito, portanto, em permanente transformação - como também já se admitiu que toda transformação implica (exige) alguma deformação, alguma alteração da forma. Mas isto não nos desobriga de meditar sobre os possíveis limites desta deformação, além dos quais toda transformação resultaria em deformidade, defeito, deficiência e, no limite, em degeneração.

24 Berque, Augustin. Médiance. De Millieux em Paysages. $2^{\alpha}$ Ed.. Paris: Belin/Reclus, 200o, pp. 48.

25 Idem, ibidem.

26 BERQUe, Augustin. "Geogramas, por uma ontologia dos fatos geográficos”. In: Geograficidade, v.1, n.1, Verão 2012, pp. 8-9.

\section{Capítulo 2}

Considerações sobre a gravidade ética e politica da paisagem e de suas transformações

Sandra Patrício e Vladimir Bartalini 
Em verdade, os caminhos para pensar esta questão que acabamos de apresentar - que a deformação da paisagem pode, ao ultrapassar certo limite, resultar em degeneração - já vêm sendo palmilhados há longo tempo, por muitos pensadores. Um destes caminhos se abre com o Timeu, diálogo que teria sido escrito por Platão já em sua velhice. Este texto antigo tem grande importância, pois geralmente se reconhece nele um dos primeiros na história do pensamento europeu a nos oferecer, correlacionadas, uma teoria do conhecer e uma teoria do ser; por outro lado, pode-se dizer que esta importância reduplicou-se ao longo dos séculos pela própria circunstância de que uma tal teorização instaurou - para o bem ou para o mal - certo modo de pensar; o que, de qualquer modo, não impediu que o Timeu possa ter chegado a se converter numa curiosidade e uma charada indecifrável"27. Apresentar aqui toda esta "charada indecifrável” seria inteiramente despropositado; mas, para que adiante se possa prosseguir ainda com Berque (em vez de multiplicar os caminhos possíveis para meditar nossa questão), é preciso, ao menos, apresentar aquilo que Platão coloca como que na "encruzilhada" entre o ser e o conhecer - e que ele designa pela palavra chôra. Só isto, porém, já é tarefa mui ingrata: obrigatoriamente, tanto cometeremos equívocos quanto poderemos ser acusados injustamente de tê-los cometido, tantas são as interpretações carreadas por tal idéia. Vamos tentar minimizar os transtornos atendo-nos a reproduzir, 
mal-e-mal, os contornos que lhe dá o próprio Platão (na tradução que, por fortuna, temos à mão) e que serão retomados por Berque ${ }^{28}$.

E, com Platão ${ }^{29}$, devemos começar por quase lastimar que nossa argumentação tenha chegado a constranger-nos a tentar tornar visível por meio de palavras esta forma difícil e indistinta ${ }^{30}$. Com tais palavras, o filósofo introduz em sua ontocosmologia um terceiro gênero de ser, que é não apenas diferente tanto daquilo que é sempre e não tem geração (as Formas eternas e imutáveis do mundo inteligível), quanto daquilo que se gera sempre e nunca é (as formas perecíveis e mutáveis do mundo sensível, geradas por imitação das Formas eternas), como ademais que é o receptáculo e como que a mãe de todas as gerações ${ }^{31}$ o que será reforçado adiante, quando insistirá em que

(...) devemos ter em consideração que há três gêneros: aquele que se gera, aquele no qual é gerado e aquele à semelhança do qual nasce aquele que se gera. E é conveniente assimilar o receptáculo a uma mãe, o modelo a um pai, e a natureza que está entre os dois a um filho ${ }^{32 .}$

28 Não nos furtaremos, porém, a oferecer desde já duas outras referências que poderão conduzir o leitor interessado a algumas das controvérias que não poderão ser contempladas em nossa exposição. São elas: MIGLIORI, Maurizio. "O problema da geração no Timeu”, In: GAzoLLA, Rachel (org.), "Cosmologias. Cinco ensaios sobre filosofia da natureza. São Paulo: Paulus, 2008, pp. 13-45; e DERRIDA, Jacques, “Khôra”, Campinas, SP: Papirus, 1995.

29 PLATÃo. “Timeu” - Introdução de José Trindade dos Santos e tradução de Maria José Figueiredo. Lisboa: Instituto Piaget, 2003.

30 PLATÃO, op. cit., $49 a$.

31 Idem, ibidem.

32 Idem, $50 d$. 
Seguem-se explicações das razões pelas quais este terceiro gênero, que recebe em si todos os gêneros, seja ele próprio desprovido de todas as Formas 33 . E logo depois:

(...) se dissermos que [a mãe e o receptáculo de tudo aquilo que se gera e é visível, e de todas as maneiras sensoriável] é uma certa forma invisivel e amorfa, que tudo contém e que participa do inteligivel da maneira mais embaraçosa e difícil de compreender, se dissermos isso, não estaremos a mentir ${ }^{34}$.

Apenas após recapitular novamente o que são os outros dois gêneros (um que é sempre gerado e nunca é, e que é passível de ser captável pela opinião; outro que nunca é gerado e é sempre, e que é investigado pelo pensamento), Platão retornará ao terceiro gênero no qual se dá a geração, e só então o nomeará:

E há ainda um terceiro gênero que é sempre, o da chôra, que não acolhe a destruição e fornece o lugar a todas as coisas que têm geração; este écaptável por meio de um certo raciocínio bastardo, não acompanhado de sensação e dificilmente crivel; para ele olhamos como num sonho, afirmando que é de certa maneira necessário que todo o ser esteja em certo lugar e ocupe um certo espaço, e que aquilo que não está na terra nem no céu nada é.35

Podemos deixar Platão neste ponto, mas não sem antes intercalar uma advertência (novamente: provavelmente desnecessária para os mais doutos, mas importante para aqueles que se iniciam nestas

33 Idem, 50e.

34 Idem, 51, $a-b$.

35 Idem, $52 a-b$. 
discussões). Não se confunda, como aliás é mais comum do que seria esperável ${ }^{36}$, o sentido da palavra chôra ao tempo de Platão, com o moderno conceito de espaço. Para a nossa discussão, procuraremos assumir o ponto de vista de Berque, que é o de ater-se a apreender o sentido que podia ter, no seu próprio contexto, uma palavra explicitamente utilizada por um autor antigo ${ }^{37}$. Considera ele (em conformidade com muitos outros comentadores) que no texto platônico uma outra palavra (topos) corresponderia ao espaço, enquanto chôra seria correspondente ao lugar. Berque vai, declaradamente, ocupar-se tão somente da questão da chôra, à partida tratando de recuperar este sentido contextual que a palavra teria ao tempo da escritura do Timeu. E reconhece nela duas famílias de sentido:

Na primeira, chôra significa o espaço ou o lugar atributivos de qualquer ser em geral, isto é, que esse atributo pode ser físico (localizável na extensão) ou social (localizável entre os papéis pessoais). (...) Na segunda (...), chôra torna-se algo de muito mais concreto, singular e preciso: é a região ou o território próprio de uma cidade-estado (polis). (...) De forma ainda mais específica, é a parte rural desse território, a que se encontra fora das murathas do astu (a cidade propriamente dita) e aquém dos confins inabitados, as eschatiais (...). Em suma, é o campo que - papel indispensável - fornece os seus víveres à polis, e do qual esta estruturalmente faz parte..$^{3}$

36 Diga-se de passagem, na própria edição de onde retiramos as citações acima, esta confusão transparece na tradução do texto platônico (embora com ressalvas elucidativas), a despeito de ter sido tematizada e esclarecida na introdução do livro.

37 Berque, Augustin. “A chôra em Platão”, op. cit., p. 30.

38 BERQUe, Augustin. "A chôra em Platão". In: SERRÃO, Adriana Veríssimo (coord.), "Filosofia da Pisagem. Um manual”. Lisboa: Centro de Filosofia da Universidade de Lisboa, 2012 (pp. 29-37), p. 32. Grifamos. 
Ele ainda destaca que estas duas famílias de sentido não seriam, ademais, estanques: argumenta que, neste contexto grego, sendo a cidade (polis) o termo primário que determina a existência do cidadão (politês), segue-se que, para o homem grego (como Platão) a noção de chôra devia estar marcada por conotações existenciais e vitais, que será preciso ter em conta, hermeneuticamente, no propósito do Timeu ${ }^{39}$.

Para o momento, o que importa sublinhar no texto de Berque é que toda esta argumentação (e outras, que omitiremos) vem amparar a interpretação de que a chôra seria, em Platão, o meio concreto onde o ser relativo existe ${ }^{40}$. E será a partir deste ponto de vista que Berque poderá concluir que, no texto platônico, a palavra chôra corresponderia ao "lugar" (ou "região"), enquanto a palavra topos corresponderia ao "espaço" - destacando ainda que, no texto do Timeu, topos corresponderia à banal questão factual: “onde está?”; ao passo que chôra corresponderia a uma questão muito mais complexa e ontologicamente mais profunda: "por que razão este onde?"41. Mas esta última questão, diz Berque, começou a ser forcluída já no próprio Timeu, como fica indicado pela desistência de Platão de definir a chôra (como se viu na citação do Timeu, supra: aquilo que não está na terra nem no céu nada é). E teria permanecido esquecida pelo pensamento europeu:

Numa palavra, este vai esquecê-la - vai esquecer, em suma, a questão: "porque haveriam os seres de ter um onde?" -, para se ater à clara definição que Aristóteles, em contrapartida, the terá dado a partir da

39 Idem, ibidem.

40 Idem, p. 29.

41 Idem, p. 31. 
noção de topos - isto é, ater-se, em suma, à questão: “onde estão os seres?”; o que, ver-se-á, é justamente forcluir (lock out) a chôra da questão do ser.42

Ora, esta forclusão da chôra da questão do ser equivale a esquecer, mais ou menos, as razões pelas quais o ser precisa ter um onde - por exemplo, esquecer as razões pelas quais a cidade precisa ter um “onde", que se faz tanto das características ambientais da região, como do modo de vida de seus cidadão, como ainda - e isto nem sempre é agradável lembrar - do modo (ao mesmo tempo natural, social, técnico e simbólico) pelo qual se consegue extrair o sustento de seus habitantes, necessariamente da natureza própria daquela região. Uma maneira rude e jocosa, mas também breve e verdadeira, de expor tais razões, pelas quais o ser precisa ter um onde, válida para o caso do ser humano, é dizer que a razão é sermos uns seres corpóreos, submetidos às necessidades próprias de nossa espécie - em suma, seres heterotróficos, que precisamos comer!

Esta questão é discutida não apenas no texto em pauta como no conjunto da obra de Berque, e também por inúmeros outros pensadores, sobretudo aqueles que se inspiram nas diversas correntes da chamada Filosofia da Vida. Cumpre dizer que fugiria ao nosso propósito presente enfrentar a discussão dos motivos e razões (diríamos: que a própria razão desconhece) pelos quais a questão tem sido forcluída, motivos e razões estes que se conjugam de forma muito mais complexa do que poderíamos explanar aqui. Vamos, então, nos restringir a indicar que Berque aponta duas pistas para esta investigação, em relação à chôra de Platão: uma será esclarecer (a) idéia de maternidade que conota a chôra.

42 Idem, p. 34.

Capítulo 2

Considerações sobre a gravidade ética e política da paisagem e de suas transformações

Sandra Patrício e Vladimir Bartalini 
A segunda, aprofundar (o) tema da trindade do ser, do meio e do devir43.

Para o momento, enfim, importará sobretudo sublinhar a concretude desta relação trinária, na qual a chôra ainda pode ser vista como um receptáculo nutriz deste nosso modo perecível, rasteiro, humilde, de ser para a morte. Será preciso enfatizar que nesta questão reside também a razão pela qual a transformação da paisagem, além de certos limites, é algo grave, que pode resultar em degeneração? E que, considerada assim, em sua concretude, a indagação sobre a gravidade das transformações visíveis na paisagem engloba uma indagação sobre o devir de todas as coisas, idéias, valores e vidas que a ocupam e habitam? Aqui, gostaríamos de enfatizar a necessidade, que antes apontamos, de meditar sobre os possíveis limites éticos que se colocam às transformações das paisagens, mercê da vontade de pessoas e, sobretudo, de grupos humanos detentores do poder de intervir sobre os lugares - gostaríamos de enfatizar que, para além destes limites, toda transformação tende a resultar em deformidade, defeito, deficiência e, no limite, em degeneração. É o que pretendemos ilustrar pelo detalhamento da linha de estudos conduzida por um de nós ${ }^{44}$, que se ocupa dos pequenos córregos ocultos na cidade de São Paulo.

A DEFORMAÇ̃̃o DA PAISAGEM: O GASO DOS GóRREgos OGULTOS DE SÃo PAULO.

É sabido que o paradigma urbanístico que acompanhou o crescimento urbano de São Paulo transformou os nossos vales flu-

43 Idem, p. 35.

44 Vladimir Bartalini. 
viais em infraestrutura viária e os nossos rios em canais de escoamento de esgotos e águas servidas. Se, atualmente, ele vem sendo questionado, ensejando propostas de reaproveitamento dos cursos d'água ainda não tamponados, seja para atender a finalidades de transporte, seja para fins recreativos ou ecológico-ambientais, a atenção da crítica tem se limitado aos cursos d'água de maior visibilidade. É, normalmente, desconsiderada toda uma rede capilar, muito mais entranhada no tecido urbano e, por isso, mais difícil de ser enquadrada em soluções gerais. Entretanto, é justamente este seu entranhar-se no espaço prosaico do cotidiano que, supõe-se, potencializaria as ações que nela viessem a incidir.

Justifica-se, assim, dirigir o foco a cursos d'água de pequeno calibre, muitos deles anônimos, situados em áreas de urbanização de tal modo consolidada que pouca ou nenhuma chance oferecem para a aplicação das soluções baseadas no destamponamento ou na "renaturalização" dos córregos. Coloca-se então o desafio de encontrar alternativas para integrá-los condignamente à vida e ao cenário urbano, mas integrá-los enquanto rios, que ainda são, apesar de continuarem ocultos.

Estariam descartadas as hipóteses de navegabilidade, dada a sua pequena dimensão, assim como as de recuperação ecológica, uma vez que, na maioria dos casos, esses córregos não poderiam vir à tona de maneira literal e terem suas margens restauradas, pois atravessam quadras densamente construídas e em zonas de urbanização há muito tempo estabelecida. As soluções “estetizantes”, sejam as edulcoradoras ou paliativas, sejam as que apelam para uma "estética trash", própria dos becos e vielas que acompanham os córregos ocultos, seriam igualmente afastadas. 
O que se pretende, num primeiro momento, é meramente fazer aparecer os indícios da existência de cursos d'água enterrados. Ainda assim não é uma tarefa fácil, uma vez que a sua conversão a infraestruturas não só os ocultou, como tentou apagar as pegadas da operação de ocultação. No entanto, como nem todo ato é perfeito, restaram vestígios. Uns são diretos, como vielas estreitas e tortuosas, em flagrante contraste com o traçado hipodâmico dos bairros em que se inserem, ou, ainda, dispositivos e adaptações insólitas que chamam a atenção do olhar interessado em detectá-los. Outros são indiretos, como terrenos ou faixas de lotes vagos, usados para o estacionamento de veículos, ou, então, para os "lava-rápidos", serviço de lavagem de automóveis, usos provisórios do solo urbano que podem ser eliminados a baixo custo, caso seja necessário intervir nas galerias subterrâneas onde os córregos foram enclausurados.

Estes, e muitos outros, são indícios de uma existência camuflada, mas só poderão remeter aos córregos ainda vivos se forem decodificados. Eles se apresentam de modo tão variável e aleatório que não chegam a constituir uma "fala" ou uma "escrita" inteligível.

Com a aceleração do crescimento urbano, vários espaços pontuados por vestígios (no mais das vezes insólitos) dos córregos ocultos passaram a sofrer forte pressão especulativa, que se expressa nos empreendimentos imobiliários destinados a camadas de renda mais elevada, provocando mudanças significativas tanto na sua estrutura física como na composição social dos seus moradores. Na operação de modernização desses lugares não há mais vez para intervenções fora das "boas normas" técnicas, para as improvisações que resultaram em aberrações expostas em cena pública. Agora a cirurgia se faz sem deixar cicatrizes. Perdem-se os vestígios da primeira negação da paisagem, ocultam-se os registros do avesso do tecido, ocorre uma sobre-ocultação. 
Ganha assim urgência levantar e preservar as marcas pontuais que persistem da ocultação inicial, pois, apesar de tudo, elas ainda podem aludir ao que está fora do alcance do olhar, enterrado e, não obstante, vivo.

Atar estes pontos, hoje soltos, atribuir-lhes novos sentidos, conferir-lhes um nexo que os traga dignamente de volta à vida urbana, se não ressuscita os cursos d'água, ao menos abre possibilidades para reanimar em nós a memória deles e, em outro nível, permite que os córregos sejam lidos numa nova chave interpretativa.

Mas o interesse desse resgate não se limita a evidenciar uma morfologia esquemática. Não basta apreender somente o esqueleto do trajeto do curso d'água sem que venham à tona a pulsação, os sons, enfim, tudo o que remete à vida do rio. Há todo um campo do imaginário a ser mobilizado para fazer emergir as águas correntes aprisionadas nos subterrâneos.

Os casos em que se pode empiricamente testar essas suposições são tão numerosos quanto diversos, frustrando qualquer esforço de generalização. No entanto, dos estudos levados a efeito até o momento ${ }^{45}$, na perspectiva aqui apresentada, já despontam, ao menos, oportunidades de percursos pedestres ou ciclísticos que interligariam córregos pertencentes a bacias distintas, alinhavando pontos bastante significativos no espaço cotidiano dos paulistanos.

45 A investigação dos córregos ocultos na cidade de São Paulo vem sendo realizada no Laboratório Paisagem, Arte e Cultura da Faculdade de Arquitetura e Urbanismo da Universidade de São Paulo, em trabalhos de pesquisa docente e também em trabalhos finais de graduação e de iniciação científica realizados por alunos da faculdade, alguns deles já publicados. Os casos estudados até o momento são: Água Preta, Verde (em Pinheiros) / "braço 1”, Uberabinha, Bexiga, Sapateiro, Aclimação, Pirituba, bacia do ribeirão Verde (em Pirituba) e seus afluentes Congo e Guiami (Vladimir Bartalini, docente); Verde (em Pinheiros) / "braço 2" (Mariana Martins Yamamoto, iniciação científica); Anhanguera (Maria João Cavalcanti Ribeiro de Figueiredo, trabalho final de graduação); Carajás e Mandaqui (Arthur Simões Caetano Cabral, iniciação científica); Piqueri (Arthur Simões Caetano Cabral, Trabalho Final de Graduação); Tiburtino (Murillo Aggio Piazzi, Iniciação científica).

Capítulo 2

Considerações sobre a gravidade ética e politica da paisagem e de suas transformações

Sandra Patrício e Vladimir Bartalini 
É o caso, entre outros, dos leitos dos córregos Sapateiro e Aclimação, associados a dois importantes parques públicos de São Paulo, respectivamente, o do Ibirapuera e o da Aclimação.

Estes dois parques, distantes aproximadamente três quilômetros entre si, contam com lagos que constituem fortes pontos de atração, mas os córregos que alimentam estes lagos foram alijados da paisagem e só se manifestam por indícios muito tênues, quando não degradados. Ao alinhavar tais indícios e tratá-los como convém, pode-se reconstituir os trajetos dos córregos, recuperando-os como conectores entre dois prestigiados espaços de lazer.

Promover, a partir da recuperação dos seus indícios pontuais, a aderência dos trajetos destes cursos d'água aos percursos do dia a dia da população, atendendo à condição indispensável de que eles remetam ao córrego pulsante e ocultado, já se configura como uma iniciativa válida para livrá-los do esquecimento definitivo, dando alguma chance para a aproximação entre paisagem e cidade.

Há ainda casos em que o córrego não está propriamente ocultado, ou seja, permanece a céu aberto, mas o seu alijamento da paisagem é tal que ele passaria por inexistente, não fossem as cheias pelas quais, periodicamente, ele se faz lembrar. Encaixa-se nesta situação o córrego Piqueri, afluente do Cabuçu de Cima, na região do Tremembé, zona norte de São Paulo. Em que pese sua significativa extensão e o fato de ainda se manter em grande parte descoberto, ele não protagoniza a paisagem e, se ele entra nela, é pela "porta dos fundos". No entanto, as oportunidades que ali se oferecem para a reversão deste quadro são promissoras, uma vez que muitos terrenos situados ao longo do seu vale permanecem desocupados ou subocupados, em que pese tratar-se de espaços fragmentados. A proposta de constituição de um parque sui generis, tirando partido da "força expressiva dos pormenores das bordas", nas palavras 
do seu autor, a partir da resignificação destes fragmentos, resignificação esta sempre intimamente associada à vivência dos espaços cotidianos que ali se verifica, foi desenvolvida no âmbito de um trabalho final de graduação ${ }^{46}$. Não caberia aqui avançar na explicitação desta proposta, mas a sua leitura cuidadosa certamente trará esclarecimentos quanto aos rumos e alcance da pesquisa sobre os córregos ocultos... ou não tão ocultos.

\section{PALAVRAS DE ENGERRAMENTO}

A situação dos córregos ocultos na cidade de São Paulo é uma dentre as muitas situações urbanas concretas, nas quais observamos os resultados sempre provisórios e questionáveis que advêm das tentativas vãs de negar, por soberba ou imperícia, a materialidade, para nós incontornável, da Terra, sobre a qual fundamos nossa existência. Estas situações demonstram, de modo insofismável, a importância ética e política da paisagem: se sua integridade (aliás, poderíamos até dizer: sua beleza) expressa formalmente a relação harmônica entre o lugar e a vida de seus habitantes, sua deformidade é sintoma de desarmonias passadas-presentes e permite vislumbrar desequilíbrios e sofrimentos futuros. Trata-se, portanto, de tema a exigir atenção teórica e pragmática extremada, se queremos "fazer a nossa parte" para preservar condições suficientemente boas para a vida, em todas as suas múltiplas manifestações - desde as formas orgânicas mais simples até todos os animais superiores; desde a vida puramente orgânica até a diversificada vida cultural dos homens; desde a vida atuada objetivamente até a vida secreta da alma humana que sente e simboliza o mundo...

46 Trata-se do trabalho denominado À beira do urbano. O espaço das águas no norte de São Paulo, de Arthur Simões Caetano Cabral, concluído na Faculdade de Arquitetura e Urbanismo da Universidade de São Paulo, em 2014, disponível em http:|/issuu.com/cabralarthur/docs/_beira_do_urbano/1

\section{Capítulo 2}


É certo que estas nossas breves considerações não são suficientes para a apreensão inteira do tema, menos ainda para a elaboração de um possível conceito definitivo de paisagem - nem pretendemos que o fosse, posto que reconhecemos a complexidade do assunto. Quisemos, sim, apresentar contributos para a superação de divergências teóricas e disciplinares que se estabeleceram ao longo do tempo - mormente daquelas que contrapõem, como se antagônicos fossem, os aspectos objetivos e subjetivos, naturais e culturais, da paisagem. Esperamos ter conseguido, ao menos, sugerir que o burilamento da noção de paisagem é um dos trabalhos que mais poderá contribuir para que o pensamento contemporâneo possa, enfim, ser capaz de superar as cisões que, digamos assim, herdou das longas errâncias do próprio pensar - e com isso, possa vir a contribuir para a restauração de nossa humana morada sobre a Terra.

Para fortalecer nosso propósito, encerramos estas notas com as sugestivas palavras de Adriana Veríssimo Serrão:

Há um modo de ser específico da paisagem, que ésujeito e objeto, permanência e movimento, mutabilidade e persistência. Material, propicia todas as sensações, sem deixar de ser intangível. Delimitada pela linha do horizonte, amplas e rasgadas a céu aberto, as paisagens condensam como exemplares únicos uma ontologia complexa: a superfície sustentada na profundidade e que se ergue em altura. É a temporalidade que unifica a diversidade do espaço: um tempo de coexistência das idades dos elementos, incluindo o humano; um tempo longo, enlace de passado, presente e futuro; um tempo que não é sentido senão pelo homem, mas é maior que o homem. ${ }^{47}$ 
